\title{
In memoriam Prof. Dr. Otto Backer Dirks
} (1917-2005)

On January 3rd, 2005, Prof. Dr. Otto Backer Dirks died. He was one of the oldest and most highly esteemed members of the 'ORCA family'. He was President of ORCA from 1958 to 1960 and a member of the Advisory Council until 1974. In 1962 he was awarded the ORCA Rolex Prize, he became an Honorary Member in 1979. These were not the only tokens of appreciation by the international research community. In 1981 the International Association for Dental Research awarded Backer Dirks the H. Trendley Dean Memorial Award.

Backer Dirks was the initiator of the Tiel-Culemborg study on the effect of water fluoridation in the Netherlands. He set high, innovative and still valuable standards for clinical research by creating a standardised method for caries evaluation. He was the first to use standardised X-ray photography in epidemiological surveys. He not only recorded the number of cavities but also several pre-cavitated stages of the caries lesion. By doing so he discovered re-mineralization in vivo and the effect of fluoride on this process; his article on this topic [J Dent Res 1966;45:503-511] is still frequently cited.

$\mathrm{He}$ also realised that clinical research has to be accompanied by more fundamental research. He stimulated both microbiological and physico-chemical research in the departments that he chaired over the years. Many successful researchers in these areas started their careers in his department or in close collaboration with him.

Backer Dirks was also greatly involved in the education of dentistry students. In 1960 he was appointed Associate Professor in Oral Microbiology and in 1965 Professor of Preventive Dentistry at the State University of Utrecht. From that time he stimulated science in the dental curricula. He also introduced behavioural sciences into the curriculum, realising the importance of conveying the message. At his retirement in 1982 he established the Backer Dirks Foundation to support students to do scientific research during their studies. After his retirement he remained very active. He did a remarkable job for the Dutch Dental Museum: unselfishly he personally phoned every Dutch dentist for a contribution to the Museum.

Backer Dirks was involved in social affairs, public dental health and public dental health education. He was the initiator of drinking water fluoridation in the Netherlands. In spite of all his effort, the goal was unfortunately not achieved. After the rejection of water fluoridation by the Dutch government, he initiated alternatives such as community-based education programs and dental clinics in which care started as early as pre-birth. In these projects he realised that co-operation with medical and social health workers was essential.

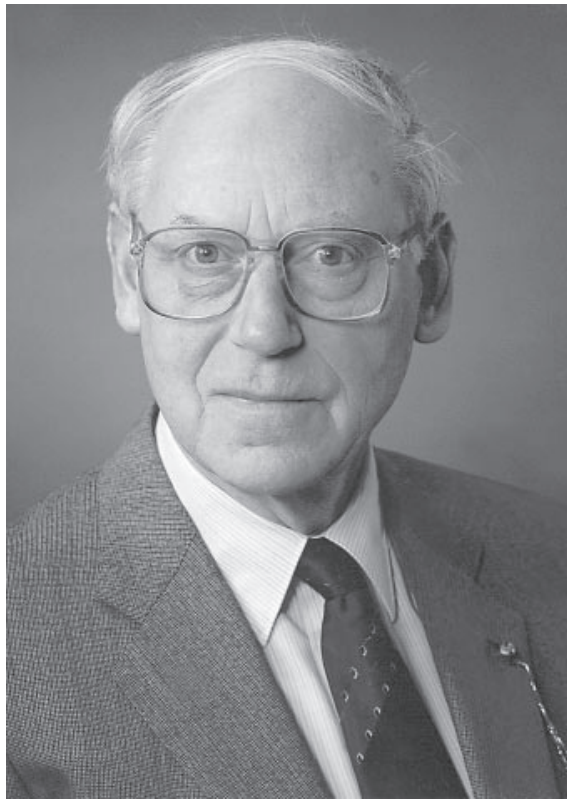

He was member or chairman of many governmental and nongovernmental boards. In all these boards he was an invaluable ambassador of preventive dentistry. His work was also appreciated outside dentistry, testified by a high royal decoration: Officer in the Order of Orange-Nassau (1965). One of the organisations has to be mentioned in more detail: Het Ivoren Kruis (The Ivory Cross). Already as a little boy he became familiar with this organisation, as his father was the president for many years and the board meetings were held in his parental home. The organisation was founded at the beginning of the 20th century for the stimulation of preventive dentistry and to deliver and provide free dental care to underprivileged children. Backer Dirks always admired his father and mother, who both were dentists, for their interest in preventive and community dentistry. In many of his own achievements, Backer Dirks always wanted to honour his parents for this.

In spite of all the time he needed for his work, Backer Dirks had always time to listen to and help solve the problems of dental students. The same was true for his co-workers, and you felt appreciated when you talked with him. At his home there was always a warm welcome for everyone, warmth that was given both by Backer Dirks and his wife.

The death of Backer Dirks is a great loss to the Dutch and international dental community. We all lose a most appreciated and prominent personality as well as an inspiring and warm-hearted friend.

Cor van Loveren

Peter van Amerongen

\section{KARGER}

Fax +41613061234 E-Mail karger@karger.ch www.karger.com
(C) $2005 \mathrm{~S}$. Karger $\mathrm{AG}$, Basel

0008-6568/05/0394-0261\$22.00/0

Accessible online at: www.karger.com/cre 